\title{
O gestor municipal na atual etapa de implantação do SUS: características e desafios
}

DOI: 10.3395/reciis.v1i2.84pt

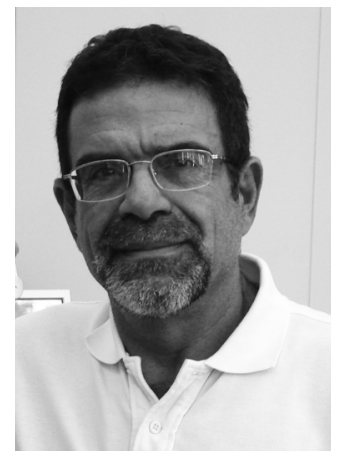

Luiz Carlos de Oliveira Cecilio Departamento de Medicina Preventiva da Universidade Federal de São Paulo, São Paulo, Brasil cecilioluiz@uol.com.br

\section{Ana Lúcia Medeiros de Souza} Departamento de Medicina Preventiva da Universidade Federal de São Paulo, São Paulo, Brasil

\section{Claudia Elisa Belinazo}

\section{Mercadante}

Secretaria de Estado da Saúde de São Paulo, São Paulo, Brasil

\section{Claudia Vega}

Secretaria de Estado da Saúde de São Paulo, São Paulo, Brasil

\section{Francisco Antonio de Castro Lacaz}

Departamento de Medicina Preventiva da Universidade Federal de São Paulo, São Paulo, Brasil

\section{Ligia Maria de Almeida}

\section{Bestetti}

Secretaria de Estado da Saúde de São Paulo, São Paulo, Brasil

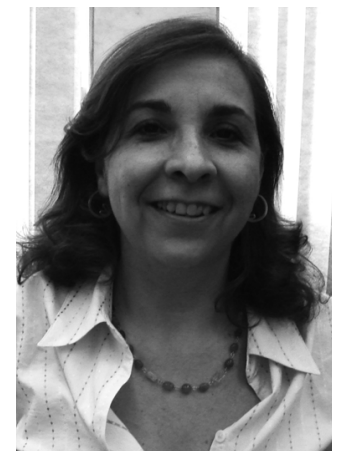

\section{Marlene Rizziolli Lima}

Secretaria de Estado da Saúde de São Paulo, São Paulo, Brasil

\section{Nicanor Rodrigues da Silva Pinto}

Departamento de Medicina Preventiva da Universidade Federal de São Paulo, São Paulo, Brasil

\section{Sandra Maria Spedo}

Departamento de Medicina Preventiva da Universidade Federal de São Paulo, São Paulo, Brasil

\section{Wanda Nascimento dos Santos Sato}

Departamento de Medicina Preventiva da Universidade Federal de São Paulo, São Paulo, Brasil 


\section{Resumo}

Desde a criação do Sistema Único de Saúde (SUS), através da lei 8080/90 e dos seus subseqüentes instrumentos de regulamentação, os municípios têm visto aumentar suas responsabilidades em relação à organização e operacionalização dos sistemas locais de saúde. O artigo apresenta os resultados de uma pesquisa qualitativa realizada junto aos gestores de 20 municípios de uma Diretoria Regional de saúde da Secretaria de Estado da Saúde de São Paulo. Procurou-se caracterizar o perfil dos gestores, suas trajetórias profissionais, se formulam e como formulam um projeto de saúde para a cidade, qual a composição de sua equipe, quais as suas estratégias para garantir o acesso aos serviços de saúde que não existem no município e qual a visão sobre o gestor estadual e sobre as instâncias intergestores existentes em sua região. O estudo revela uma grande heterogeneidade entre os gestores municipais predominando, porém, uma baixa capacidade para formular, implementar e avaliar políticas municipais de saúde. O artigo ressalta a necessidade de estratégias de educação permanente dos gestores para o exercício de suas funções.

\section{Palavras-chave}

Gestor municipal, política de saúde, sistemas municipais de saúde, municipalização, descentralização, SUS (BR), gestão em saúde

\section{Introdução}

Desde a criação do Sistema Único de Saúde (SUS), através da lei 8080/90 e dos seus subseqüentes instrumentos de regulamentação, os municípios têm visto aumentar suas responsabilidades em relação à organização e operacionalização dos sistemas locais de saúde. Esse movimento de descentralização, de um conjunto importante de responsabilidades e de recursos das esferas superiores do sistema para os municípios é reconhecido, hoje, como uma verdadeira reforma setorial do Estado. A municipalização é um processo em curso e como tal precisa ser melhor estudada e compreendida nos seus aspectos positivos e avanços, mas também em suas limitações, contradições e dificuldades para que estratégias de apoio e desenvolvimento institucional possam ser desenvolvidas.

A partir da década de 1990, o Ministério da Saúde (MS) tem se utilizado de Normas Operacionais para balizar o funcionamento do SUS, em particular as crescentes responsabilidades assumidas pelos municípios e os mecanismos de pactuação intergestores. Entre estas, duas são especialmente importantes: as Normas Operacionais Básicas (NOB) 01/93 e 01/96.

A NOB 01/93 estabeleceu, entre outras coisas: o repasse regular e automático, fundo a fundo (do MS para os municípios), por teto histórico; a criação das instâncias colegiadas de direção do sistema como a Comissão Intergestores Tripartite (CIT) composta por representantes do MS, o Conselho Nacional de Secretários de Saúde (CONASS) e o Conselho Nacional dos Secretários Municipais de Saúde (CONASEMS), no âmbito nacional e a Comissão Intergestores Bipartite (CIB) composta por representantes do estado, do Conselho Estadual dos Secretários Municipais de Saúde (COSEMS), no âmbito estadual; reforçou a exigência da Lei 8.142 de que os estados e os municípios constituíssem seus fundos, conselhos, planos, relatórios e contrapartida de recursos; estabeleceu os critérios de habilitação dos municípios em gestão incipiente, parcial e semiplena dos sistemas municipais de saúde.
A NOB 01/96 manteve instâncias de pactuação e integração previstas na NOB 01/93 como a CIT e as CIBs, que atuam como fóruns entre gestores do SUS visando à pactuação e programação das atividades de saúde e à definição de tetos financeiros dos sistemas municipais e estaduais, e ampliou as funções dos municípios no que se refere à gestão dos sistemas de saúde, definindo duas modalidades de gestão: a plena da atenção básica e a plena do sistema municipal (BRASL, 1997).

A Norma Operacional da Atenção à Saúde (NOASSUS) 01/2002, em seu capítulo da regionalização, instituiu o Plano Diretor Regional (PDR), que é um instrumento de ordenamento do processo de regionalização e fundamenta-se na conformação de sistemas funcionais e resolutivos de assistência à saúde com o objetivo de garantir a integralidade da assistência e o acesso da população aos serviços e ações de saúde de acordo com suas necessidades. A partir de então, discriminam-se os seguintes conceitos-chave: região de saúde; módulo assistencial; município sede do módulo assistencial; município pólo; e unidade territorial de qualificação na assistência à saúde (BRASIL, 2002).

Para investigar a extensão dessa reforma, é preciso avaliar qual é a presença dos municípios na realização das funções acima apontadas, o que implica considerar alguns traços característicos daqueles que se propõem a assumir a gestão da política de saúde e suas relações com os níveis regionais e estaduais de gestão do sistema. Tais características estão relacionadas a questões de diversas naturezas e envolvem

“(...) capacidades administrativas e financeiras dos governos locais, [o] legado das políticas prévias, (...) novas regras do jogo e (...) dinâmicas política e eleitoral [que impactam] a produção de políticas públicas no plano local (ARRETCHE et al., 2002, p.456).

Apesar de reconhecidas dificuldades, o processo de descentralização de gestão da saúde tem sido implementado de forma gradual e consistente desde a década de 1990. A concretização da diretriz da descentralização 
da saúde em um país com dimensões continentais e tantas desigualdades regionais, implica grandes desafios, tais como: não perder a unicidade de uma política de caráter nacional e respeitar a diversidade do contexto sócio econômico, bem como a conformação da oferta de serviços como construção social. Nesse sentido, as NOBs e a NOAS do SUS foram consideradas instrumentos estratégicos e fundamentais, por possibilitarem a regulação do processo de descentralização, tratando de aspectos relacionados à divisão de responsabilidades, relações entre gestores, critérios e mecanismos de transferência de recursos federais para estados e municípios (LEVCOVITZ et al., 2001, p. 270-73).

Estudos sobre a descentralização/municipalização da saúde, em municípios brasileiros selecionados, fornecem indicações sobre possíveis condicionantes do processo de construção do SUS no país. Um desses condicionantes está relacionado à autonomia financeira e de pessoal qualificado no município para que este incorpore, além da atenção básica, a integralidade da atenção à saúde (VIANA et al., 2002, p. 484-87; MARQUES et al., 2003, p. 403-14).

Por outro lado, sabe-se que a maioria dos municípios, por suas características de espaço/território e sócio-demográficas, tem baixo grau de suficiência de seus serviços e ações de saúde e, por isso, há grande dependência de serviços localizados em municípios maiores, o que ressalta a necessidade da regionalização efetiva dos serviços de saúde (NEPESS, 2005, p.149).

A descentralização da gestão da saúde deve ser parte de um processo de constituição de sistemas locais de saúde que, por um lado, respondam adequadamente às necessidades da população e, por outro, sejam elementos e elos dinâmicos de articulação regional com o sistema nacional; em contrapartida, não deveria culminar com a constituição de sistemas isolados e autônomos (SCATENA et al., 2001, p.71-73).

Esse processo de descentralização, em curso, tem propiciado um campo fértil à experimentação prática e instrumental em planejamento e organização de serviços de saúde. Os gestores municipais vêm se constituindo como importantes atores sociais no cenário políticoinstuitucional do SUS e, ainda que de forma limitada, propiciando espaço para a experimentação de novos modelos e práticas, visando à superação de diversidades presentes em vários municípios e regiões do país.

O CONASEMS defende a tese de que

“a municipalização, ao contrário do que dizem alguns críticos do processo, não foi uma 'municipalização autárquica e sim uma municipalização incompleta, que foi realizada sem que se superassem todos os constrangimentos financeiros necessários para a execução adequada das políticas".

Ainda, para aquele órgão

(...) o termo municipalização 'autárquica' é inadequado, ao desconsiderar os constrangimentos que reduziram a possibilidade do município expandir serviços de forma suficiente para atender as necessidades de seu município e dos municípios de referência. É também inapropriado porque os municípios, ao contrário de maior liberdade de gestão, estão tendo redução de sua autonomia em decorrência da tendência de transferência vinculada e fragmentada de recursos financeiros aos municípios. Temos, de fato, que construir alternativas urgentes para garantir o fluxo e o acesso dos usuários entre os municípios. A solução para isso não é intervir na gestão local. É, pelo contrário, ampliar a autonomia para que sejam criadas condições de construção de eficácia compatíveis com as diferentes realidades locais -radicalizando a municipalização- e construir pactos de gestão em que participem todos os atores loco-regionais (município-pólo, municípios de referência, representantes regionais em gestor estadual) que adeqüem o modelo regional às necessidades e superem, solidariamente, as dificuldades de acesso a todos os níveis de atenção" (CONASEMS, 2005, p.15).

Em contrapartida, há autores para os quais um dos problemas da atual etapa de implantação do SUS seria exatamente o que eles denominam de "municipalização autárquica”, isto é, a gestão dos sistemas de serviços de saúde no âmbito local ser de responsabilidade maior do município, com pouca ou nula participação dos outros níveis de governo. Para esses autores, cada município se transforma em um sistema fechado, com deseconomia de escala, fragmentação de serviços e perda de qualidade (PESTANA et al., 2004, p.11).

Para o CONASEMS, o processo de municipalização teve dois momentos. O primeiro correspondeu ao início do processo, com a municipalização da atenção básica e implantação das gestões semiplenas, quando os municípios conquistaram autonomia da gestão. Houve muitos avanços nesta etapa, em particular a ampliação do acesso da população aos serviços assistenciais, com impacto positivo sobre os indicadores de saúde.

"No segundo momento, que teve início mais ou menos no final da década de 1990, passou a haver uma excessiva normatização burocrática, que levou a uma redução da autonomia da gestão. Os municípios passaram a responder às políticas induzidas centralmente - com diferentes graus de protagonismo em decorrência da heterogeneidade desse processo - e a administrar conflitos e dificuldades do modelo vigente" (CONASEMS, 2005, p.14).

Neste sentido, estudar e compreender a atual etapa da construção do SUS, em particular o que está acontecendo, de fato, na assistência prestada nos municípios, passa, necessariamente, pela compreensão de duas questões interligadas: a capacidade de gestão dos gestores municipais frente às suas crescentes e complexas responsabilidades e a articulação regional entre municípios, com a intermediação e apoio do gestor estadual, na sua representação regional. Ainda para o CONASEMS,

"houve uma expressiva redução do papel assistencial das secretarias estaduais de saúde e indefinição de seus papéis na regulação do fluxo e acesso dos pacientes entre os municípios. Essas dificuldades, como era de se esperar, geraram 
descontentamentos entre os atores locais, disputas entre municípios e ampliaram demandas reprimidas nas áreas de média e alta complexidade em muitas regiões do país, que se avolumaram ainda mais" (CONASEMS, 2005, p.15).

O Pacto pela Saúde (pela Vida, em Defesa do SUS e de Gestão), editado em 2006, sintetiza a mais recente política do Ministério da Saúde no sentido de estabelecer as atribuições dos vários entes governamentais na configuração do SUS, incluindo aí os municípios. O Pacto tem a pretensão de imprimir mudanças significativas na execução do SUS, entre as quais: a substituição do atual processo de habilitação pela adesão solidária aos Termos de Compromisso de Gestão; a regionalização solidária e cooperativa como eixo estruturante do processo de descentralização; a integração das várias formas de repasse dos recursos federais e a unificação dos vários pactos hoje existentes (BRASIL, 2006).

Finalizamos esta apresentação, retomando uma recomendação expressa no documento do CONASEMS:

"É necessário estimular estudos sobre as gestões descentralizadas nas suas diferentes variáveis, inclusive as que analisam pacto federativo, governabilidade e governança locais, poder local, democratização, eficiências de políticas descentralizadas etc. Os estudos de caso existentes não estão sendo suficientes para analisar essas diferentes dimensões" (CONASEMS, 2005, p.16).

O presente estudo pretendeu dar alguma contribuição no sentido de uma melhor compreensão de tais questões.

\section{Metodologia}

Este artigo foi organizado utilizando-se os dados obtidos em uma pesquisa intitulada "O gestor estadual $e$ os gestores municipais na construção do sistema loco-regional de saúde: desafios da gestão descentralizada do Sistema Único de Saúde (SUS)", realizada com recursos CNPq/Fapesp, entre 2005 e 2007. A “pesquisa-mãe" tinha como objetivo geral identificar e analisar o papel do município e as relações que se estabelecem entre os gestores municipais e o gestor estadual, em uma Diretoria Regional de Saúde da Secretaria de Estado da Saúde (SES-SP), visando à garantia da integralidade do cuidado e na perspectiva da descentralização da gestão do SUS. Os objetivos específicos eram: a) caracterizar a estrutura político-administrativa dos municípios estudados para fazer frente às tarefas e atribuições decorrentes do processo de municipalização, em particular a capacidade e governabilidade para construir pactuações que garantam a integralidade do cuidado; b) caracterizar a visão dos gestores municipais e do gestor estadual, no nível regional, a respeito do papel dos municípios, do gestor estadual e das demais instâncias de gestão do SUS, na garantia da integralidade da assistência. Para a elaboração deste artigo foram utilizados os dados referentes aos gestores municipais. Os dados e análises sobre o gestor estadual serão apresentados em um próximo artigo.
O estudo apontou que a "falta de dinheiro novo", embora tenha peso importante, não explica todas as dificuldades atuais e futuras no processo de regionalização no estado de São Paulo. Apresentamos e discutimos, neste trabalho, algumas características do processo de gestão municipal que precisam ser enfrentadas na perspectiva de se avançar na construção do SUS.

A opção metodológica foi um estudo de caso, em sua variante de estudo de casos múltiplos, que se caracteriza por envolver mais de um caso com a mesma estrutura metodológica do estudo de caso único. Nesse tipo de estudo, a escolha dos casos é norteada pela possibilidade de que cada caso possa prever resultados semelhantes ou produzir resultados contrastantes apenas por razões previsíveis (YIN, 2005, p. 68-70).

Ainda do ponto de vista metodológico, utilizamos o conceito de isomorfismo organizacional, que seria a potencialidade que o estudo restrito de um grupo ou de um número determinado de municípios tem de fornecer indicações que possam ser generalizadas para um conjunto mais amplo. Pela abordagem institucional,

“as organizações funcionam mediante a incorporação de orientações previamente definidas e racionalizadas na sociedade, que contribuem para a legitimação das suas atividades e para sua sobrevivência, independente da eficiência e da demanda da sua produção" (FONSECA, 2003, p.52).

O conceito de isomorfismo organizacional destaca o fato de que, sob a pressão de determinados fatores externos comuns, as organizações vão se tornando cada vez mais parecidas entre si. $\mathrm{O}$ isomorfismo coercitivo seria aquele decorrente de organizações operando num mesmo contexto legal, econômico e político e de pressões formais e informais exercidas pelo Estado. Em tais contextos, as organizações adotam estratégias de funcionamento similares e vão ficando cada vez mais parecidas entre si.

"O isomorfismo é vantajoso para as organizações, pois a similaridade facilita as transações interorganizacionais e favorece seu funcionamento por regras socialmente aceitas. (...) Ao que parece, para os institucionalistas, é a conformidade aos valores e normas sociais, ou a legitimidade, mais do que o desempenho, o que determina a sobrevivência das organizações" (FONSECA, 2003, p.54-55)

Trabalhamos com a hipótese inicial, a partir do conceito de isomorfismo, de que os gestores municipais de saúde, a despeito das especificidades e singularidades dos seus municípios, vão ficando cada vez mais parecidos entre si, devido ao fato de estarem submetidos ao mesmo conjunto de regras e normas, que vão da Lei da Responsabilidade Fiscal aos vários mecanismos de financiamento que o Ministério de Saúde tem adotado; dos mecanismos previstos de controle social às mesmas exigências dos vários sistemas de informação e prestação de contas. Seria o conceito de isomorfismo social que nos permitiria, em princípio e como opção metodológica, fa- 
zer generalizações a partir da observação de um número limitado de gestores locais de saúde.

O estudo foi realizado em uma diretoria de saúde da Secretaria de Estado da Saúde de São Paulo. Foram selecionados oito municípios para o estudo. Para tanto, foi feita uma estratificação dos municípios em função de duas variáveis: (a) o porte dos municípios - população menor que 20.000 habitantes, de 20.000 a 100.000 habitantes, e acima de 100.000 habitantes; e (b) o tipo de gestão - gestão plena do sistema municipal (GPSM) e gestão plena da atenção básica ampliada (GPAB-A).

A estratificação dos municípios resultante da combinação destas duas variáveis é apresentada na Tabela I.

\section{Tabela 1 - Estratificação de municípios de acordo com porte populacional e tipo de gestão}

\begin{tabular}{c|c|c}
\hline $\begin{array}{c}\text { Tipo de } \\
\text { Município }\end{array}$ & População & Tipo de Gestão \\
\hline A & $>100.000$ & GPSM \\
B & $20.000-100.000$ & GPSM \\
C & $20.000-100.000$ & GPAB-A \\
D & $<20.000$ & GPAB-A \\
\hline
\end{tabular}

Fonte: Pesquisa “O gestor estadual e os gestores municipais na construção do sistema loco-regional de saúde: desafios da gestão descentralizada do Sistema Único de Saúde (SUS)”. CNPq/Fapesp (2005-2007).

Foram eleitos dois municípios de cada tipo (A, B, C e D), perfazendo um total de oito municípios. A seleção final dos municípios participantes foi feita com a participação de técnicos da diretoria regional e apresentada e aprovada na Comissão Intergestores Regional (CIR). Um critério para a seleção dos municípios foi o fato de seus gestores estarem participando dos dois fóruns de educação permanente conduzidos pela diretoria regional e que abrangem 20 municípios.

O material empírico da pesquisa foi obtido a partir de dois procedimentos metodológicos: entrevista semiestruturada com os gestores dos municípios escolhidos e observação participante dos pesquisadores nos dois fóruns de educação permanente (FEP) mantidos pela diretoria regional estudada, dos quais os gestores dos municípios escolhidos participam regularmente (quatro de cada FEP).

Os FEPs são encontros mensais, que ocorrem de forma itinerante em um dos municípios participantes. $\mathrm{O}$ município que recebe os componentes da reunião mensal do FEP se responsabiliza pela infra-estrutura organizacional (espaço físico, equipamentos didáticos, alimentação, entre outros). As pautas dos encontros são elaboradas tanto a partir das demandas dos gestores, como de oferta de temas feita pela coordenação do FEP. Nos encontros, são apresentadas situações vividas pelos gestores, e, conforme as necessidades do grupo e suas vivências, vão sendo reelaboradas novas pautas. Os temas são aqueles de interesse comum, podendo ir desde a discussão de novas portarias, leis e decretos, a temas como a organização do processo de trabalho, a dificuldade de acesso à média e alta complexidade, a gestão do trabalho em saúde e em particular, gestão do trabalho médico, entre outros. A partir desses encontros, vão sendo desenhadas estratégias para o possível enfrentamento das situações apresentadas, sempre na perspectiva de se aumentar a "caixa de ferramentas", conceitual e instrumental, dos gestores.

Os pesquisadores participaram por período superior a um ano de todos os encontros dos FEPs, o que os tornou espaços privilegiados de observação das práticas, problemas, pautas, dificuldades vividas pelos gestores municipais hoje. Reiterando, então, para fins de clareza: o material empírico da pesquisa, no que se refere aos gestores municipais, foi coletado a partir de entrevistas semi-estruturadas com oito gestores municipais e da observação-participante nos FEPs, que abrangem 20 gestores, incluindo os oito entrevistados.

O projeto de pesquisa foi aprovado pelo Comitê de Ética da Universidade Federal de São Paulo. Tanto os gestores municipais entrevistados como os que participam dos FEPs assinaram Termo de Consentimento Livre e Esclarecido, após serem devidamente informados sobre os objetivos da pesquisa.

\section{Resultados}

A gestão municipal, idealizada pelo projeto da Reforma Sanitária Brasileira como mais eficaz, porque “estaria mais próxima dos cidadãos”, e mais sensível aos seus anseios, só tem se realizado em parte. É grande a diversidade observada entre os gestores, predominando os que não têm formação e nem experiência na gestão da “coisa pública”. É escassa a compreensão do SUS como política pública e de que o gestor municipal teria como eixo de sua prática a garantia de tal política no nível municipal. O estudo mostrou como os gestores municipais, de um modo geral, desconhecem a história de lutas e da construção do SUS. As concepções do SUS variam do "SUS é prevenção" ao "SUS como plano de saúde".

Observou-se uma grande rotatividade dos gestores municipais no período do estudo. Um dos municípios estudados teve duas mudanças na gestão da saúde, ou seja, três gestores em um ano! Isso, somado ao despreparo e ao descompromisso ideológico com o "SUS enquanto política" é um importante problema a ser enfrentado.

Os gestores municipais, em particular os dos municípios menores, não contam com nada parecido com uma "equipe de governo", com capacidade e experiência para planejar, implantar políticas e avaliar os impactos da gestão em saúde. É imensa a sobrecarga dos gestores com o conjunto de tarefas impostas, em ritmo crescente, pelos "níveis superiores" do sistema.

A lógica dos "núcleos profissionais" se impõe, independente de um eventual projeto de governo.

A maioria dos municípios estudados não tem um plano municipal de saúde ou não sabe produzir um plano, ou não se utiliza de um plano de saúde como instrumento 
real de gestão, de estabelecimento de prioridade e para avaliação e prestação de contas de suas atividades. É exceção encontrar um município que, pelo menos, se utilize de indicadores para conhecer, em alguma medida, as necessidades de saúde da população e, a partir daí, organizar sua gestão.

Os gestores estão com sua atenção voltada para uma demanda aparentemente sem fim por consultas de especialidades, procedimentos, cirurgias, cobradas com aflição pelos usuários e com impaciência pelos profissionais de saúde, em particular os médicos. Um evento grave (e agudo) nos municípios pequenos, que exija o acesso ágil a um atendimento mais complexo, pode tomar um dia inteiro de trabalho direto e pessoal do gestor.

Os gestores não conseguem formular bem qual o "modelo assistencial" que desejam para a cidade. Há um certo "consenso discursivo" de que o Programa de Saúde da Família (PSF) seria uma boa saída, mas praticamente nenhum dos gestores entrevistados o tem como seu "eixo estruturante". Nos municípios convivem modelagens assistenciais diferentes, quais sejam, PSF, centro de saúde "tradicional" (organizado por "áreas" da mulher, adulto e criança) e mesmo unidades que fazem puramente o "pronto-atendimento". Alguns poucos municípios conseguem ter algo parecido com "programação em saúde", isto é, reconhecer grupos prioritários e desenvolver ações regulares, programadas, educativas, desenvolvidas por equipe multiprofissional. Mas, isto é exceção. Os municípios que têm equipes de PSF não conseguem avaliar sua efetividade, de modo que o PSF funciona mais como estratégia de captação de recursos do nível federal.

Todos os municípios das duas micro-regiões estudadas que possuem hospitais privados, particularmente vinculados às Santas Casas, subsidiam estes hospitais sem uma contrapartida clara das contribuições do hospital para o SUS municipal. São crescentes os gastos com os hospitais, embora os gestores não consigam negociar nenhuma contrapartida assistencial, e tampouco exercer qualquer tipo de controle sobre como é feita a atenção hospitalar. São necessários estudos mais aprofundados sobre a relação do gestor municipal com os hospitais.

Todos os municípios contratam especialistas e produzem exames complementares, em geral, via terceirização, de forma que vários municípios, além da sua rede básica, contam com especialidades médicas. Apesar de, em várias situações, a produção mensal, no município, ultrapassar os parâmetros estabelecidos pela Portaria $N^{\circ}$ 1.101 do Ministério da Saúde, fica sempre a sensação de que o "problema não está resolvido", entre outras coisas, porque os especialistas geram demanda de procedimentos que não são realizados no município. Existem grandes filas de espera em todos os municípios. Há indicações de precarização da força de trabalho em toda a região estudada que precisaria ser melhor caracterizada em outras investigações. Precarização foi entendida, no estudo, como a utilização de força de trabalho sem vínculo formal com a instituição e, por conseqüência, sem a garantia dos direitos trabalhistas garantidos pela legislação. Um bom exemplo disso é a "contratação" de médicos através de empresas. Há várias situações de terceirização tanto de profissionais como de serviços inteiros. Boa parte dos municípios pequenos entrega a composição e "gestão" do seu corpo clínico a um médico que "abre uma empresa” e "contrata" médicos para trabalhar na rede. O fenômeno da precarização não é visto como problema pelos gestores. Ao contrário, é "solução".

Os médicos continuam sendo importantes para abrir portas dos níveis de atenção. A maioria dos municípios estudados se utiliza da contratação de médicos "com contatos" para conseguir encaminhamentos para determinados serviços. Os gestores afirmam claramente que na hora da contratação de um médico, vale o "QVC", isso é, "quem você conhece". Os gestores denominam tal rede paralela e informal de regionalização de "rede clandestina". Circular em tal rede implica, muitas vezes, no pagamento de alguma "complementação" por parte do paciente. Ou seja, a entrada é via SUS, mas a realização do cuidado se faz numa lógica privada. Os gestores médicos se utilizam de seus contatos e conhecimentos para conseguir encaminhamentos de pacientes.

Os gestores municipais, sejam eles médicos ou não, são reféns da lógica de funcionamento da Instituição Médica e não têm como enfrentá-la. Os gestores não conseguem, com exceções pontuais, fazer algo parecido com a "gestão do trabalho médico", qual seja, do controle do horário e produtividade à qualidade do cuidado prestado pelos médicos. Há, no entanto, pequenos ensaios no sentido da adoção de protocolos clínicos nos serviços básicos com grande resistência por parte dos médicos. Os gestores não têm quadros ou "equipe" para realizar tal tarefa. Há experiências, ainda iniciais, de construção de alguns indicadores como, por exemplo, a relação entre exames solicitados/consultas realizadas. A baixa adesão dos médicos ao “projeto SUS" é apontada como uma das explicações para a baixa resolutividade da rede e pelos encaminhamentos para média e alta complexidade considerados excessivos, mais do que por "despreparo técnico".

Nesse sentido, o avanço da regionalização vai depender, em boa medida, dos gestores municipais conseguirem construir novas relações com os médicos, em particular, da implementação de "regras do jogo" mais claras para as práticas profissionais. Essas novas regras deverão ser construídas de forma negociada e dialogada, mas poderão resultar em novas tensões entre gestores e médicos, na medida em que implicarão maior controle e cobrança.

Os gestores dos municípios-pólo se sentem sobrecarregados com o atendimento de pessoas dos outros municípios e avaliam que o que recebem do SUS não cobre suas despesas. Atender as “invasões" (esse é o termo utilizado) prejudica o atendimento dos próprios municípios. Esses gestores são os que têm mais queixas em relação ao que eles avaliam como a pouca participação da SES/SP no financiamento do sistema.

Em relação ao Fundo Municipal de Saúde, há várias situações ou arranjos, em cada um dos municípios: desde o gestor fazer o controle efetivo da aplicação dos recursos, cabendo ao secretário da Administração ou de Finanças "apenas assinar o cheque", até situações em que o gestor 
municipal de saúde tem dificuldade de acesso e acompanhamento da gestão do fundo. Como conseqüência, fica ainda menor a governabilidade do gestor para conduzir a política municipal de saúde.

\section{Conclusões}

A hipótese inicial de que estaria ocorrendo o "isomorfismo organizacional", isto é, que os gestores municipais estariam cada vez mais parecidos entre si, em função de determinantes externos, no nosso caso, as diretrizes do SUS e seus mecanismos de financiamento, só se confirmou em parte. De fato, se, por um lado, os gestores municipais, ao lidarem com problemas parecidos e estarem submetidos a um conjunto comum de constrangimentos político-administrativos, acabam apresentando uma pauta muito parecida de dificuldades e focos de atenção, por outro, é grande a diversidade de arranjos, dispositivos, práticas, composição de equipes, modos de se fazer a gestão experimentados. O que os torna parecidos é uma "pauta de problemas" bem homogênea, com destaque para a dificuldade em se garantir a integralidade do cuidado aos munícipes, em particular no que diz respeito ao acesso à média e alta complexidade. Essa parece ser a face mais dramática e mais tensionadora do cotidiano de todos os gestores. É o que parece fazêlos mais iguais entre si: a sensação de serem reféns de uma demanda sem fim por serviços que não podem ser realizados em seus municípios. Esse é o foco de atenção inicial e recorrente em todos os encontros dos FEPs.

Por outro lado, o tamanho do município, em particular a complexidade da rede de serviços de saúde de que dispõe, parece ser um fator determinante na variabilidade observada entre os gestores. Mas não é o único: o contexto político local, em particular o prestígio e governabilidade do gestor municipal junto ao prefeito, $o$ maior ou menor grau de ingerência política na "máquina" da secretaria de saúde, a composição e experiência da sua equipe de governo (muitos gestores municipais são "departamentos de saúde" e não secretarias de saúde), a trajetória pessoal do gestor e sua capacidade de formulação de um projeto de saúde para a cidade, a existência de atores sociais com alguma capacidade de controle sobre o SUS, o projeto político pessoal do gestor municipal e sua articulação político-partidária local, tudo isso resulta em uma grande diversidade de configurações das equipes gestoras municipais.

O processo de municipalização posterior à aprovação da Lei Orgânica da Saúde e de toda a legislação infraconstitucional subseqüente foi conduzido de forma direta entre o Ministério da Saúde e os municípios, com pouca ou quase nenhuma intermediação das secretarias estaduais de saúde, ao contrário do que havia ocorrido no processo de implantação das Ações Integrais de Saúde (AIS) e do Sistema Unificado e Descentralizado de Saúde (SUDS) na década de 1980. Tal fato se traduz, no atual momento, na pouca presença e capacidade de apoio técnico-operacional e financeiro para os gestores municipais por parte da Secretaria de Estado da Saúde, através de seus órgãos regionais.
Assim, a descontinuidade político-administrativa nos municípios, a grande rotatividade e o despreparo dos gestores municipais, com baixa capacidade de formulação, implementação e avaliação de políticas locais, fazem da baixa capacidade de governo dos gestores municipais um tema estratégico na atual etapa de implantação do SUS. Até mesmo porque, muitas vezes, sequer existem "equipes" que dêem conta da complexidade das tarefas postas para o município hoje. Diante de tal constatação: quais as estratégias mais adequadas para enfrentar essas deficiências? De quem seria a responsabilidade de condução de processos de preparo dos gestores municipais atuais e dos que virão em um fluxo constante nas próximas eleições?

Se considerarmos que $75 \%$ dos municípios possuem menos de 20.000 habitantes, dispõem de estruturas organizativas bastante precárias e padecem de todos os problemas apontados no estudo - da rotatividade dos gestores ao seu despreparo para o exercício de suas funções - pensamos poder afirmar que o mesmo, apesar de conduzido junto a vinte gestores municipais, aponta para um conjunto de questões de abrangência nacional.

O Ministério da Saúde, ao editar, em 2006, as portarias 399 e 699 que instituem o Pacto pela Saúde (pela Vida, pelo SUS e de Gestão), está buscando, de alguma forma, dar conta das questões que estamos apresentando. O Pacto pode ser visto como um grande esforço no sentido de contribuir para que os gestores municipais consigam imprimir uma direcionalidade para os sistemas municipais de saúde pautada pelos princípios e diretrizes do SUS. Apesar de sua legitimidade, construída através de longas negociações com as representações dos gestores em todos os níveis (CONASS, CONASEMS, Conselho Nacional de Saúde - CNS), o Pacto corre o risco de se tornar mais um instrumento normativo, sem força para imprimir as mudanças necessárias, se não levar em conta as reais condições em que os gestores municipais estão trabalhando hoje.

\section{Referências bibliográficas}

ARRETCHE, M.; MARQUES, E. Municipalização da Saúde no Brasil: diferenças regionais, poder do voto e estratégias de governo. Ciência \& Saúde Coletiva, Rio de Janeiro, v.7, n.3, p.455-479, jul.-set. 2002.

BRASIL, Ministério da Saúde. Gestão Plena com Responsabilidade pela Saúde do Cidadão. Norma Operacional Básica do Sistema Único de Saúde/ NOB-SUS 96. 1997

BRASIL, Ministério da Saúde. Regionalização à saúde: aprofundando a descentralização com equidade. Norma Operacional à Saúde - NOAS-SUS 0 1/2002. Portaria MS/GM n.373, de 27 de fevereiro de 2002, e regulamentação complementar. Brasília, 108 p., 2002

BRASIL, Ministério da Saúde. Portaria/GM 399, 22/02/2006. Divulga o Pacto da Saúde 2006 - Consolidação do SUS e aprova as Diretrizes Operacionais do Referido Pacto. 2006. 
Conselho Nacional de Secretários Municipais de Saúde (CONASEMS). Teses e Plano de Ação: 2005-2007. Brasília (DF), 2005. Disponível em: <http://www.conasems.org.br>. Acesso em: 11 out. 2005.

FONSECA, V.S. A abordagem institucional nos estudos organizacionais: bases conceituais e desenvolvimentos contemporâneos. In: Vieira M.M.F.; Carvalho A.C. (Orgs.). Organizações, Instituições e Poder no Brasil. Rio de Janeiro: FGV, 2003. 324 p.

LEVCOVITZ, E.; LIMA, L.D.; MACHADO, C.V. Política de saúde nos anos 90: relações intergovernamentais e o papel das Normas Operacionais Básicas. Ciência \& Saúde Coletiva, Rio de Janeiro, v.6, n.2, p.269-291, jul.-dez. 2001.

MARQUES, R.M.; MENDES, A. Atenção básica e programa de saúde da família (PSF): novos rumos para a política de saúde e seu financiamento? Ciência \& Saúde Coletiva, Rio de Janeiro, v.8, n.2, p.403-14, abr.-jun. 2003.

NEPESS (Núcleo de Estudos e Pesquisas de Sistemas de Saúde). Estudo analítico e prospectivo sobre as relações entre concepção de distrito sanitário e as diretrizes de regionalização expressas na NOAS (Relatório Técnico). São Paulo, 2006. 239 p.

PESTANA, M.; MENDES, E. M. Pacto de Gestão: da municipalização autárquica à regionalização cooperativa. Belo Horizonte: Secretaria de Estado da Saúde, 2004. $175 \mathrm{p}$.

SCATENA, J.H.G.; TANAKA, O.Y. Os instrumentos normatizadores (NOB) no processo de descentralização da saúde. Saúde e Sociedade, São Paulo, v.10, n.2 p. 47-74, mai.-ago. 2001. Disponível em: <http://www.apsp.org. br/saudeesociedade $>$. Acesso em: 20 set. 2005.

VIANA, A.L.A. et al. Descentralização no SUS: efeitos da NOB-SUS 01/96. In: NEGRI B., VIANAA. L. A. (Orgs.). O Sistema Único de Saúde em dez anos de desafio. São Paulo: Sobravime/Cealag, 2002. p. 471-488.

YIN, R.K. Estudo de Caso: planejamento e métodos (1984). Trad. de Grassi D. Porto Alegre: Bookman, 2005. $212 \mathrm{p}$.

\section{Sobre os autores}

\section{Luiz Carlos de Olineira Cecilio}

Possui graduação em Medicina pela Universidade de Brasília (1974), especialização em Saúde Pública pela Universidade Federal de São Paulo (1977) e doutorado em Saúde Coletiva pela Universidade Estadual de Campinas (1993). É Professor Adjunto do Departamento de Medicina Preventiva da Escola Paulista de Medicina da Universidade Federal de São Paulo, em regime de dedicação exclusiva, desde junho de 2006. Foi Médico Sanitarista da Secretaria de Estado da Saúde de São Paulo de 1977 a 2006, comissionado como docente do Departamento de Medicina Preventiva e Social da Universidade Estadual de Campinas (Unicamp) de 1994 a 2005. Além disso, desde a década de 80, é consultor de várias instituições públicas de saúde, sempre na perspectiva da implantação de modos de se fazer a gestão mais democráticos e participativos. Sua atual linha de pesquisa é "Política, Planejamento e Gestão em Saúde". Atua no programa de pós-graduação em Ciências da Saúde do DMP da Unifesp, ministrando a disciplina "Teoria da Organização e Gestão em Saúde", orientando trabalhos de pós-graduação e coordenando projetos de pesquisa.

\section{Rosemarie Andreazza}

Possui graduação em Nutrição pelo Centro Universitário São Camilo (1983), mestrado em Epidemiologia pela Universidade Federal de São Paulo - Unifesp (1993) e doutorado em Saúde Pública pela Universidade de São Paulo (2000). Desde 1989 é Professora do departamento de Medicina Preventiva da Unifesp. É membro da equipe responsável pela implementação/desenvolvimento do campo de Saúde Coletiva na Unifesp, com ênfase na área da política, planejamento e gestão em saúde, desde 2000 e também membro do grupo de pesquisa do CNPq de Política, Planejamento e Gestão em Saúde. Além disso, desde 2001 acompanha e atua junto às instâncias institucionais de reformulação curricular; coordenando atualmente o núcleo de articulação Universidade Serviços de Saúde, vinculado ao Programa Nacional de Reorientação da Formação de Profissionais de Saúde (Pró-Saúde) dos cursos de Medicina e Enfermagem. Seus principais temas de interesse são: a educação permanente em saúde, os processos de transformação da formação dos profissionais de saúde e o desenvolvimento das políticas de saúde visando à construção e o fortalecimento do Sistema Único de Saúde (SUS). 